\title{
REPRESENTAÇÕES SOCIAIS DA SAÚDE E DOENÇA E IMPLICAÇÕES PARA O CUIDAR EM ENFERMAGEM: UMA ANÁLISE ESTRUTURAL ${ }^{1}$
}

\author{
SOCIAL REPRESENTATIONS OF HEALTH AND DISEASE AND THE \\ IMPLICATIONS FOR CARE TAKING IN NURSING: A STRUCTURAL \\ ANALYSIS \\ REPRESENTACIONES SOCIALES DE LA SALUD Y ENFERMEDAD E \\ IMPLICACIONES PARA EL CUIDADO EN ENFERMERIA: UN ANÁLISIS \\ ESTRUCTURAL
}

Denize Cristina de Oliveira ${ }^{2}$ Celso Pereira de Sá ${ }^{3}$

\begin{abstract}
RESUMO: Este estudo objetivou a caracterização das representaçōes sociais do processo saúdedoença de individuos residentes em dois municipios de São Paulo, com vistas à identificação das necessidades de saúde e à orientação da ação de enfermagem. Foram coletadas evocações livres de 418 adultos sobre os temas "saúde" e "doença". Realizou-se uma análise descritiva e estrutural das representaçōes sociais, através da metodologia de construção do quadro de quatro casas, categorização e análise de similitude. Os resultados indicam como sentidos centrais da representação, a positividade da "saúde", ancorada em uma entidade divina, acompanhada de noçōes que associam a saúde à prevenção de doenças, necessidades biológicas, atividade e à atitude assumida frente à doença. A estrutura da representação de "doença" apresenta-se semelhante, conquanto em sentido inverso, à da "saúde": deus è estruturador da representação, em sua versão negativa, expressando-se no corpo através da dor, da morte e da inatividade e, no espirito, através da tristeza e do desânimo. Discute-se o caráter psicológico da saúde e da doença, que se expressa sob a forma de necessidades psicossociais comprometidas, e a conseqüente necessidade de repensar o modelo tecnológico de trabalho em enfermagem.
\end{abstract}

PALAVRAS-CHAVE: cuidar em Enfermagem, Necessidades Humanas Básicas, Saúde-Doença, Representações Sociais

\section{INTRODUÇÃO}

O presente estudo se fundamentou na teoria geral das representações sociais (JODELET, 1989, MOSCOVICI, 1976), tendo se valido também dos métodos e técnicas desenvolvidos no âmbito da sua abordagem estrutural complementar (ABRIC, 1994, SÁ, 1996).

A Teoria de Representações Sociais tem como uma de suas hipóteses fundadoras o abandono da distinção entre sujeito e objeto de pesquisa. Parte-se, nessa perspectiva, da tese de que não existe, a priori, realidade objetiva, mas que toda realidade é representada, ou seja, apropriada pelo individuo e pelo grupo, reconstruida no seu sistema cognitivo, integrada ao seu sistema de valores, dependente de sua história e do contexto social e ideológico no qual está

\footnotetext{
1 Pesquisa financiada pela FAPESP, processo 99/02201-4.

2 Enfermeira, Doutora em Saúde Pública, Pós-Doutorado em Psicologia Social, Professora Titular da Faculdade de Enfermagem da Universidade do Estado do Rio de Janeiro.

${ }^{3}$ Professor Titular do Instituto de Psicologia da Universidade do Estado do Rio de Janeiro.
} 
inserido. (MOSCOVICI, 1976)

Considera-se, portanto, que é essa realidade apropriada e reestruturada que constitui a própria realidade para o individuo e para o grupo. Toda representação é, portanto, uma forma de visão global e unitária de um objeto. Essa representação possibilita a reestruturação da realidade de modo a permitir uma integração simultânea das caracteristicas objetivas do objeto, das experiências anteriores do indivíduo e do seu sistema de atitudes e de normas.

Dessa forma, reconhece-se uma certa visão funcional do mundo uma vez que a representação permitiria, ao indivíduo e ao grupo, dar um sentido às suas condutas e à compreensão da realidade através do seu próprio sistema de referências, portanto adaptar-se ao mesmo e posicionar-se (DOISE; CLEMENCE; LORENZI-CIOLDI et al., 1992).

Vista desta forma, a representação é concebida como "uma forma de conhecimento, socialmente elaborada e compartilhada, com um alcance prático que contribui para a construção de uma realidade comum a um conjunto social" (JODELET, 1989, p.36). Ela é "o produto e o processo de uma atividade mental, através da qual um individuo ou um grupo reconstitui o real com o qual ele é confrontado e atribui a ele um significado específico" (ABRIC, 1987, p.64).

Assim concebida, a representação não é um simples reflexo da realidade, mas uma organização significativa que depende, ao mesmo tempo, de fatores contingentes - natureza e dificuldades colocadas pela situação, contexto imediato, finalidade da situação - e de fatores mais gerais que ultrapassam a própria situação - contexto social e ideológico, lugar do individuo na organização social, história do individuo e do grupo, relações de poder socialmente estabelecidas (ABRIC, 1994).

Nas suas relações com as práticas, a representação funciona como um sistema de interpretação da realidade que rege as relações dos individuos com seu ambiente fisico e social determinando, desta forma, suas práticas; pode-se caracterizá-la, ainda, como um guia para a ação, uma vez que ela orienta as ações e as relações sociais; finalmente, deve-se considerá-la como um sistema de pré-decodificação da realidade, porque ela determina um conjunto de antecipações e de expectativas (ABRIC, 1998).

É dentro desse posicionamento teórico que se optou por direcionar este trabalho, na busca de elementos conceituais que possibilitem a instrumentalização da prática de enfermagem. Essa instrumentalização teórico-conceitual será buscada na articulação do conceito de necessidades humanas básicas, com a teoria das representações sociais.

Dentre muitos dos impasses enfrentados atualmente pela área de enfermagem, já amplamente discutidos por diversos autores, um deles não mereceu uma atenção especifica até o momento. Trata-se da reflexão acerca da permanência (como pertinente) ou, ao contrário, da superação, no momento social e histórico em que vivemos, do conceito de "necessidades humanas básicas", privilegiado originalmente na enfermagem brasileira por Horta (1979) e, no contexto americano, por Meleis (1985).

A hipótese aqui levantada é a da potencialidade desse conceito como elemento subjacente às práticas, que exerceria um papel definidor das práticas profissionais de saúde, em função dos fatores apontados a seguir.

Primeiramente, porque o conceito de "necessidades" perpassa as diversas construções teóricas da enfermagem e dos outros campos da saúde, explicita ou implicitamente. Em segundo lugar, porque, concebida como cuidado, como propõe Waldow (1998), a prática de enfermagem supõe algum grau de reconhecimento do que seja universalmente concebido como necessidades e de qual seja a compreensão do seu atendimento. $O$ terceiro ponto refere-se aos esforços de Horta (1979) para delinear uma "teoria das necessidades humanas básicas" como suporte para a prática de enfermagem e, sobretudo, ao grande impacto que essa articulação teórica teve (e ainda parece ter) na orientação do fazer na enfermagem brasileira, o que pode ser evidenciado pelo grande número de pesquisas que se utilizam, na atualidade, desse referencial.

Necessidades humanas, conforme definido por Fawcett (1995 p. 22), apesar de manter uma postura critica em relação ao seu uso, afirma que, como categoria de conhecimento da 
enfermagem,

\begin{abstract}
....as necessidades focalizam as funçöes de enfermagem e consideram o paciente em termos de uma hierarquia de necessidades. Quando os pacientes não podem atender as suas próprias necessidades, os cuidados de enfermagem são requeridos. A função da enfermeira é de prover as açöes necessárias para ajudar o paciente a atender as suas necessidades.
\end{abstract}

Desta forma, problematizar o saber em enfermagem implica em recorrer às concepções de "necessidades humanas" que lhe dão suporte, com vistas à superação de uma dimensão biológica e normativa e à construção de uma dimensão social e universal. Buscar um enfoque das necessidades humanas pautado no bem-estar coletivo e social está estreitamente ligado a uma concepção politica e moral do que seja o ser humano.

Essa afirmativa está amparada, de um lado, na constatação de que o mundo moderno tem como uma de suas caracteristicas a transformação rápida das coisas e das necessidades, como forma de implementar o consumo. Sustenta-se, de outro lado, na verificação da falência dos paradigmas que deram suporte aos diversos campos que compõem a saúde, historicamente, e de que essas transformações têm como um dos seus subprodutos a mudança na concepção do que seja necessário ou essencial à vida, isto é, implica um processo de transformação das representações sociais acerca das "necessidades humanas" e, sobretudo, das formas de manifestação dessas necessidades. A esse respeito, Santos (1994) afirma que:

As sociedades contemporâneas e o sistema mundial em geral estão passando por processos de transformação social muito rápidos e muito profundos que põem definitivamente em causa as teorias e os conceitos, os modelos e as soluçōes anteriormente considerados eficazes para diagnosticar e resolver as crises cruciais... (p.9)

A questão que toca mais diretamente ao campo da enfermagem, proposta para reflexão neste trabalho, è a premência da busca de novos enfoques e conceitos que contribuam para o caminhar desse campo de conhecimento rumo à sua constituição interna e, fundamentalmente, a melhor compreender e definir a sua articulação ao campo de conhecimento da saúde, bem como ao plano das politicas sociais.

Para o desenvolvimento dessa tarefa, buscamos problematizar o conceito de "necessidades humanas básicas", com vistas à emergência de uma proposição conceitual ancorada na sua importância como conceito fundamental para o campo da saúde e, particularmente, da enfermagem.

Partindo da premissa de que o objeto deste estudo comporta compreensões distintas, a polissemia em si dos termos "necessidades", "saúde" e "doença" pode ser vista como constituindo o próprio objeto de estudo.

Dentro do contexto proposto, o objetivo geral deste estudo consistiu em caracterizar as representações sociais do processo saúde-doença de individuos pertencentes a familias de baixa renda, residentes nos municipios de Monteiro Lobato e Santo Antônio do Pinhal, SP, com vistas à identificação das necessidades de saúde dessa população e à orientação da ação profissional para seu atendimento, particularmente o processo de cuidar em enfermagem.

\title{
METODOLOGIA
}

Foram estudados 418 sujeitos adultos, através da aplicação de um questionário contendo questões de evocações livres sobre os temas indutores "saúde" e "doença". Foi realizada uma análise descritiva e estrutural das representações sociais, através de uma estratégia metodológica 
que envolveu a construção do quadro de quatro casas para análise das evocações livres e a análise de similitude.

A análise das evocações livres foi realizada segundo técnica especifica, com utilização do software EVOC-versão 2 (VERGĖS, 1999), que fornece os dados estatísticos para a construção do quadro de quatro casas (distribuição das evocações em quadrantes) (VERGĖS, 1992). O eixo horizontal do quadro representa o valor da freqüência média dos termos evocados, o vertical informa a média das ordens médias ponderadas de evocação dos mesmos termos, ou seja, a quantificação da importância atribuida ao termo em função da ordem que ocupa no conjunto dos dicionários produzidos. Os termos evocados, assim distribuidos, possibilitam a análise do conteúdo e da estrutura da representação. Tomando a distribuição dos termos pelos quadrantes, pode-se descrever a organização do conteúdo da representação: seu provável núcleo central e elementos periféricos. Considerado o conjunto das evocações e sua categorização, pode-se visualizar o conteúdo integral da representação.

A segunda técnica utilizada foi a categorização dos termos produzidos pelos entrevistados, segundo orientação semântica e de significados dos termos analisados, constituindo um conjunto mais sintético e que abarca o conjunto das evocações livres. Para essa categorização parte-se dos termos localizados nos quatro quadrantes, distribuindo-se o conjunto das evocações em categorias compostas por esses termos, e acrescentando-se outras categorias na medida que as iniciais revelem-se insuficientes para abarcar o conjunto dos termos.

A análise de similitude, proposta por Flament (1986), é definida como uma outra maneira de classificar os termos de uma produção discursiva, baseando-se em um coeficiente de semelhança. A análise de semelhança pode ser definida resumidamente da seguinte maneira:

admite-se que dois itens serão mais próximos na representação quanto mais elevado for o número de individuos que os tratem da mesma maneira, que aceitem os dois ou que rejeitem os dois ao mesmo tempo; em seguida calcula-se um coeficiente de contingência que é um indice de semelhança clássico. (p.141)

Desta forma, a análise de similitude pode ser considerada como uma análise de distância entre os elementos de uma produção discursiva, podendo-se determinar através dela os elementos que co-ocorrem, que "vão juntos" numa produção discursiva. Efetua-se, nesse tipo de análise, as seguintes etapas: definição de categorias discursivas, a partir do conjunto de palavras produzidas na evocação livre; cálculo das freqüências médias das categorias; análise de coocorrência das categorias, determinando a força das ligações através de análise de semelhança e construção de matrizes de semelhança (KENDALL ou KRUSKAL); as matrizeş de semelhança resultantes do programa $\mathrm{EVOC}^{4}$ e SIMI ${ }^{5}$ são tratadas pelo programa AVRIL para a construção de "árvores representacionais", um gráfico que expressa a força de ligação entre as categorias; a interpretação desse gráfico vai possibilitar a confirmação ou o abandono da hipótese de centralidade resultante da construção do quadro de quatro casas.

\section{RESULTADOS}

\section{ANÁLISE DAS EVOCAÇÕES E CONSTRUÇÃO DO QUADRO DE QUATRO CASAS}

Serão apresentados a seguir os quadros de quatro casas construídos para as evocações aos termos "saúde" e "doença", seguidos da distribuição das categorias descritivas dos mesmos

\footnotetext{
${ }^{4}$ EVOC - Conjunto de programas que permitem a análise de evocações. (VERGĖS, 1997)

${ }_{5}^{5}$ SIMI - Análise de similaridade de questionários e de dados numéricos. (VERGES, 1999)
} 
Representações sociais da saúde...

termos em novo quadro, o que possibilitará uma visualização comparativa e sua discussão. QUADRO 1 - ANÁLISE DE EVOCAÇŐES AO TERMO INDUTOR "SAÚDE", MONTEIRO LOBATO E SANTO ANTÔNIO DO PINHAL - SÃO PAULO -2000

Freqüência Média « 35

Freqüência Min. « 10

Ordem Média de Evocação « 2,1

\begin{tabular}{|c|c|c|c|c|c|}
\hline Termo evocado & frequência & ordem evoc. & Termo evocado & frequência & ordem evoc \\
\hline bom & 80 & 1,438 & trabalhar & 104 & 2,423 \\
\hline deus & 74 & 1,743 & alimentação & 67 & 2,373 \\
\hline bem-estar & 49 & 1,531 & ter-coragem & 54 & 2,222 \\
\hline higiene & 49 & 2,000 & alegria & 43 & 2,186 \\
\hline importante & 35 & 1,371 & médico & 43 & 2,302 \\
\hline remédio & 33 & 2,091 & felicidade & 34 & 2,147 \\
\hline tudo & 30 & 1,700 & dormir & 18 & 3,056 \\
\hline nao-sentir-dor & 25 & 1,640 & diversão & 17 & 3,529 \\
\hline sem-preocupação & 16 & 1,938 & saúde & 17 & 2,118 \\
\hline não-sentir-nada & 15 & 1,733 & viver-bem & 17 & 2,176 \\
\hline curar & 14 & 1,643 & andar & 16 & 2,313 \\
\hline melhorar & 10 & 1,900 & primeiro lugar & 13 & 2,231 \\
\hline \multirow[t]{4}{*}{ remédio } & 33 & 2,091 & cuidar-se & 13 & 2,154 \\
\hline & & & familia & 11 & 2,818 \\
\hline & & & sem-doenca & 11 & 2,273 \\
\hline & & & força & 10 & 2,300 \\
\hline
\end{tabular}

Observa-se, nas evocações produzidas ao termo indutor "saúde", que a distribuição dos mesmos nos quadrantes apresenta-se uniforme entre os planos. No quadrante superior esquerdo, observa-se a presença das palavras bom e importante, indicando uma dimensão valorativa associada à saúde, que apresentam respectivamente a maior freqüência do quadrante e o primeiro e segundo lugares em importância em função da ordem de evocação; seguidas das palavras deus, bem-estar e higiene, que indicam respectivamente uma dimensão espiritual e estados/ necessidades especificas para o alcance da saúde. Dessa forma, a hipótese de centralidade da representação está ancorada em conteúdos avaliativos positivos, numa entidade espiritual e em práticas cotidianas de prevenção de doenças.

Observa-se nos quadrantes próximos (superior direito e inferior esquerdo), a presença de palavras que indicam outros sentidos da representação. A maior freqüência apresentada em todas as evocações ao termo saúde encontra-se no quadrante superior direito relativa à palavra trabalhar, indicando um conteúdo que associa a saúde à possibilidade de se manter em atividade, o que atribui à mobilidade física e à produtividade destaque relevante na representação. Ainda nesse quadrante, observa-se a presença de termos que indicam que a saúde está associada ao estado psicológico, como: alegria; a reafirmação das necessidades fisicas e das medidas preventivas associadas à saúde, em alimentação; e a associação da saúde a um termo com sentido bastante particular, expresso em ter coragem. Essa expressão remete a saúde ao seu estado de "força", não apenas física, mas também psiquica, moral e religiosa. É uma expressão bastante usual em cidades do interior de São Paulo e manifesta uma atitude de enfrentamento assumida diante do risco à saúde (ou da doença), o que garantiria a permanência da saúde. Essa última categoria, que apresentou elevada freqüência e uma ordem de evocação que a destaca das demais, não foi referida em estudos anteriores sobre o mesmo tema e merece destaque particular, uma vez que ela não se confunde com outros termos presentes nos quadrantes e revela um conteúdo específico. No quadrante inferior esquerdo, observa-se a presença de termos que concebem a saúde em oposição à doença, como: remédio, não sentir dor, não sentir nada, curar, melhorar. Observa-se ai ainda um reforço ao caráter psicológico e a um conteúdo avaliativo inespecifico da saúde, presentes em sem preocupação e em tudo. 
Os elementos periféricos da representação, que se situam no quadrante inferior direito, revelam uma maior aproximação da saúde ao bem estar psicológico e social, expressos em felicidade, diversão, viver bem, familia e força. Reafirmam também a indicaçăo de necessidades em dormir, saúde, sem doença e cuidar-se, além de andar, que manifesta a necessidade de atividade, todas elas associadas a uma dimensão preventiva.

O que se observa nesta análise, de uma forma geral, é a afirmação da positividade da saúde, ancorada na imagem de uma entidade divina como um dos sentidos centrais da representação, acompanhado de noções que associam a saúde à prevenção de doenças, a necessidades biológicas, à atividade, à ausência de doenças e à atitude diante da doença. Os elementos periféricos da representação, mais nitidamente prescritivos de comportamentos e de práticas, revelam principalmente que saúde é um bem psicológico e social, que necessita ser resguardado através dos cuidados de prevenção de doenças.

As necessidades de saúde que podem ser inferidas através das evocações são: 1 . necessidades biológicas, como dormir e comer; 2 . necessidade de conforto fisico e psicológico, presentes em bem-estar, não sentir dor, não sentir nada; 3. necessidades psicossociais, presentes em alegria, diversão, familia; 4 . necessidades espirituais, especificadas em deus, tudo, ter coragem; 5 . necessidades morais e de cidadania, presentes em trabalhar e viver bem.

QUADRO 2-ANÁLISE DE EVOCAÇÕES AO TERMO INDUTOR "DOENÇA", MONTEIRO LOBATO E SANTO ANTÔNIO DO PINHAL - SÃO PAULO -2000

Freqüência Média « 31

Freqüência Min. « 13

Média de Evocação « 2,1

\begin{tabular}{|lll|llc|}
\hline Termo evocado & \multicolumn{1}{l|}{ frequência } & ordem evoc. & Termo evocado & frequência ordem evoc. \\
\hline deus & 45 & 2,044 & desânimo & 36 & 2,11131 \\
dor & 37 & 2,081 & & & \\
tristeza & 102 & 1,500 & & & \\
ruim & 75 & 1,453 & & & \\
\hline cancer & 13 & 1,846 & dor-cabeça & 25 & 2,160 \\
morte & 30 & 1,933 & médico & 21 & 2,619 \\
acamado & 13 & 1,692 & remédio & 29 & 2,759 \\
& & & nervoso & 16 & 2,250 \\
& & preocupação & 25 & 2,560 \\
& & sofrimento & 21 & 2,333 \\
& & inatividade & 25 & 2,320 \\
& & não-trabalhar & 30 & 2,200 \\
& & não-se- & 26 & 2,538 \\
& & alimentar & & \\
& & & sem-coragem & 16 & 2,313 \\
& & & falta-dinheiro & 15 & 3,400 \\
\hline
\end{tabular}

A análise das evocações produzidas ao termo indutor "doença" apresenta uma configuração um pouco diferente da observada em saúde. Os elementos provavelmente centrais da representação sobre a doença, constantes do quadrante superior esquerdo, são os seguintes: a noção de deus, concebido como entidade divina não generosa que castiga através da doença; uma noção psicológico/afetiva, expressa em tristeza, que apresenta a maior freqüência, além de ocupar o segundo lugar em importância dentre as evocações, assumindo aqui um sentido duplo de causa e conseqüência da doença; a dimensão fisica da doença, expressa pela dor; e a reafirmação de um conteúdo avaliativo negativo associado à ausência de saúde, expresso em ruim, que pode ser destacado como o termo mais importante dentre as evocaçôes, em função 
da sua ordem de evocação.

Os elementos intermediários, presentes nos quadrantes superior direito e inferior esquerdo, sublinham a dimensão psicológica, em desânimo, e a objetivação da doença, em acamado, câncere morte.

Os elementos periféricos, no quadrante inferior direito, consistem em: situar, novamente, a doença por oposição à saúde, o que se observa em dor-de-cabeça, médico e remédio; reafirmar a dimensão de atitude e afetividade, em nervoso, preocupação, sofrimento e sem coragem; propor a falta de atividade como componente intrinseco da doença, observado em inatividade e em não trabalhar. Os elementos periféricos revelam ainda uma dimensão social especifica não observada quanto à saúde, traduzida por falta de dinheiro.

A estrutura da representação de doença, portanto, apresenta-se semelhante, conquanto em sentido inverso, à da saúde, apontando para a seguinte especificidade: deus é estruturador da representação, em sua versão negativa, expressando-se, no corpo, através da dor, da morte e da inatividade e, no espirito, através da tristeza e do desânimo. As práticas relativas à doença apresentam-se indicadas nos elementos periféricos, que ressaltam o sofrimento físico e psicológico representado pela doença, a incapacidade de reação ou mudança de atitude que acompanha os estados patológicos e o estabelecimento de uma relação de determinação da doença pelas condições econômicas, representada pela falta de dinheiro.

As necessidades comprometidas pela doença que podem ser inferidas das evocações são: 1 . necessidades biológicas, tal como năo se alimentar; 2 . necessidade de conforto físico e psicológico, presente em dor e dor de cabeça; 3 . necessidades psicossociais, presentes em tristeza, desânimo, nervoso, preocupação e sofrimento; 4. necessidades espirituais, especificadas em deus e sem coragem; 5 . necessidades sociais, presentes em falta de dinheiro e não trabalhar.

\section{CONSTRUÇÃO DE CATEGORIAS E ANÁLISE DE SIMILITUDE}

O conjunto das evocaçōes produzidas passaram por um tratamento que envolveu a construção de um sistema de categorias empiricas, a classificação das respostas em função desse sistema e a quantificação de cada categoria. Os resultados são apresentados em forma quantitativa, e em seguida distribuidos no quadro de quatro casas, segundo os mesmos critérios adotados para as evocações. Essa apresentação é precedida de uma descrição qualitativa das categorias definidas para saúde e para doença - que lhes são comuns.

- Estado do Corpo: Esta categoria define a saúde e a doença em função das manifestações fisicas, ou seja, suas manifestações no corpo concreto, expressas por sintomas na doença, ou por sinais na saúde. Os "sintomas", nesta concepçäo, assumem quase o lugar da doença, anulando a hipótese de existência de um processo interno ao corpo, que se manifesta apenas parcialmente na aparência externa.

- Estado Psicológico: Aqui, concebe-se a saúde e a doença em termos de um estado mental ou de processos que envolvem estados afetivos, sentimentos ou qualidades pessoais, expressos como estados psicológicos manifestos. Esses estados e processos assumem tanto o caráter de determinação quanto de expressão da saúde e da doença. A categoria parece falar de uma concepção de saúde e de doença que é prioritariamente determinada pelo estado psicológico do sujeito, quase como um atributo ou qualidade pessoal inerente a ele.

- Atividade: Esta é uma categoria já descrita na literatura e encontrada em pesquisas anteriores. Refere-se à saúde como expressa na capacidade fisica de movimento, de manter o deslocamento do corpo, de trabalhar (no sentido de executar o trabalho, não apenas de estar inserido no mercado de trabalho), de estar realizando as atividades da vida cotidiana. A doença é definida por oposição à saúde, como incapacidade de trabalhar, de movimentar-se, de manter um convivio social fora da casa. Da mesma forma que na categoria estado psicológico, a atividade parece colocar-se no lugar da doença ou da saúde, quase como se ocupasse o seu 
lugar. Assim, não se define um estado interno e outro externo; a atividade, como expressão externa, passa a ser a própria saúde e a doença.

- Estado Espiritual: Esta expressa a determinação do processo saúde-doença. A saúde é definida como um estado temporário, dado como prêmio pela força da fé de cada sujeito, do mesmo modo que a doença apresenta-se como expressão de uma forma de castigo de um deus mau, que premia os crentes com a saúde e pune os descrentes com a doença. Assim, a saúde apareceria como uma dádiva e não como um estado a ser cultivado, da mesma forma que doença assumiria um caráter de externalidade. A causalidade é sempre externa e mistica.

- Estado Sócio-Cultural: Esta categoria define o processo saúde-doença por referência ao contexto social mais amplo, à cultura e ao conhecimento. Outro atributo desta categoria é a associação desse processo à sua expressão nos relacionamentos interpessoais. A cultura $e$ particularmente o conhecimento - expresso nos depoimentos como inteligência -, assumem um caráter determinante da saúde, da mesma forma que a sua ausência parece determinar a doença. Um outro atributo desse processo é a sua expressão nos relacionamentos interpessoais e na relação de dependência originada da doença.

- Atitude no Cotidiano: Esta categoria não foi observada em outros estudos sobre as representações da saúde e da doença e apresenta contornos próprios. Refere-se a uma concepção de saúde e de doença que associa esses processos a uma predisposição interna do sujeito, ou seja, estar com saúde é sinônimo de "ter coragem", "ter vontade", "estar disposto $a^{\prime \prime}, e^{t} c$. Trata-se, ao mesmo tempo, de um atributo físico, psicológico e social, mas que não se limita a esses planos isoladamente, compondo uma dimensão da saúde e da doença ligada à "força" que mantém a vida. Essa força interna é, ao mesmo tempo, fisica e mental, e assume um caráter de determinante do processo saúde-doença. Tudo se passa como se, na ausência dessa força, a vida se extinguisse.

A análise quantitativa das respostas, segundo as categorias acima definidas, será apresentada a seguir. Cabe observar, no gráfico abaixo, a saliência das quatro categorias que apresentam as maiores freqüências: Estado psicológico; Estado do corpo; Atitude no cotidiano e Atividade. Essas quatro dimensões se repetem tanto nas concepçōes de saúde quanto nas de doença, ao serem tratadas isoladamente.

\section{GRÁFICO 1 - FREQÜÊNCIA DAS CATEGORIAS DESCRITIVAS DAS EXPRESSŌES “ESTAR COM SAÚDE" E "ESTAR DOENTE" EM RESPOSTAS EXPONTÂNEAS (SAP E ML, SÃO PAULO, 2000)}

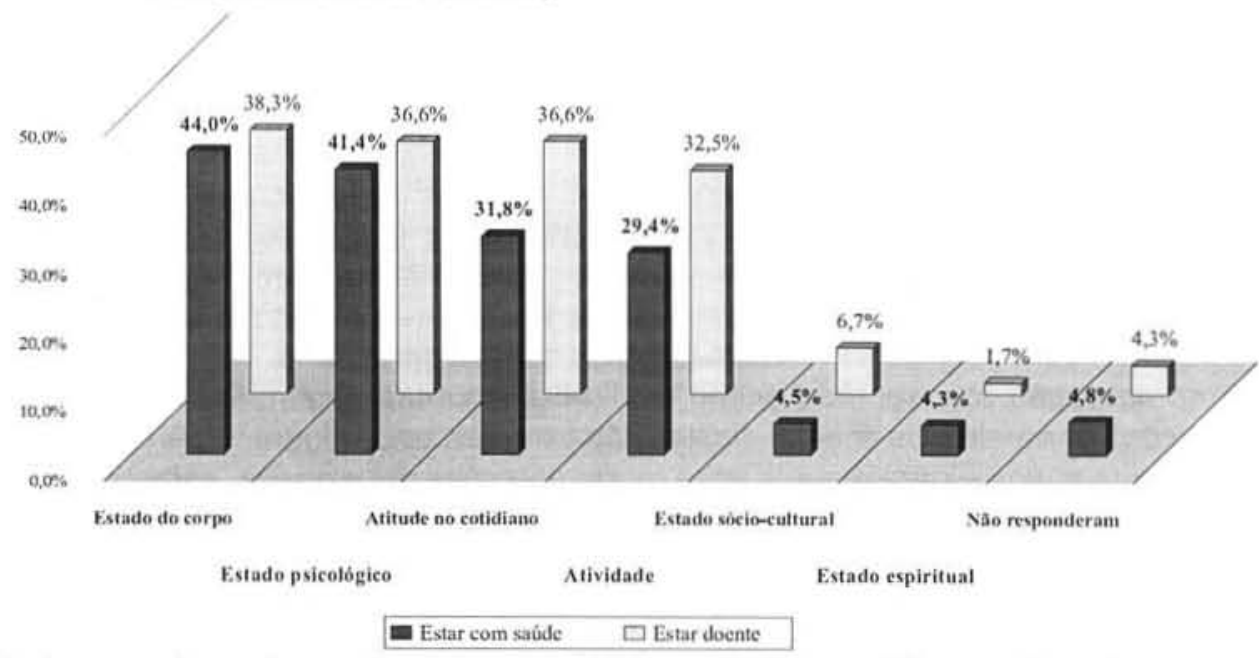

NOTA: A soma dos valores ultrapassa os $100 \%$ porque a questão que deu origem ao gráfico admitia mais de uma resposta 
Observa-se que a categoria Estado do corpo é aquela que apresenta as maiores freqüências percentuais, $44 \%$ e $38,3 \%$, nas respostas espontâneas dos entrevistados aos termos "saúde" e "doença", respectivamente. O comportamento geral das distribuições apresenta uma diferença que se refere à estabilidade dos percentuais entre as quatro categorias principais de doença $\mathrm{e}$ um decréscimo continuo em saúde, passando esta de $44 \%$, na categoria que ocupa o primeiro lugar, para $29,4 \%$ na quarta categoria. Observa-se uma diferença na ordem das frequeências e no posicionamento das categorias em relação ao termo doença, onde a categoria Atividade assume uma importância semelhante às categorias Estado do corpo e Estado psicológico.

As categorias minoritárias são Estado sócio-cultural e Estado espiritual nas duas análises. No entanto, Estado espiritual merece uma consideração a parte, uma vez que tem a sua maior freqüência em relação à saúde e a menor freqüência dentre todas em relação à doença. Em relação à categoria Estado sócio-cultural observa-se o mesmo comportamento da anterior, mas de forma invertida, ou seja, maior percentual para doença e menor para saúde.

As categorias constituídas foram, conforme quadro abaixo, distribuidas no quadro de quadro casas, conforme os mesmos critérios definidos para a análise de evocações. Mostrase, num único desenho de quadrantes, as categorias que agregam as evocações de saúde e de doença, indicando-se, em negrito, aquelas que são comuns aos dois termos indutores.

QUADRO 4 - ANÁLISE DE EVOCAÇŐES AGRUPADAS EM CATEGORIAS AOS TERMOS INDUTORES "SAÚDE" E "DOENÇA", MONTEIRO LOBATO E SANTO ANTÔNIO DO PINHAL - SÃO PAULO - 2000

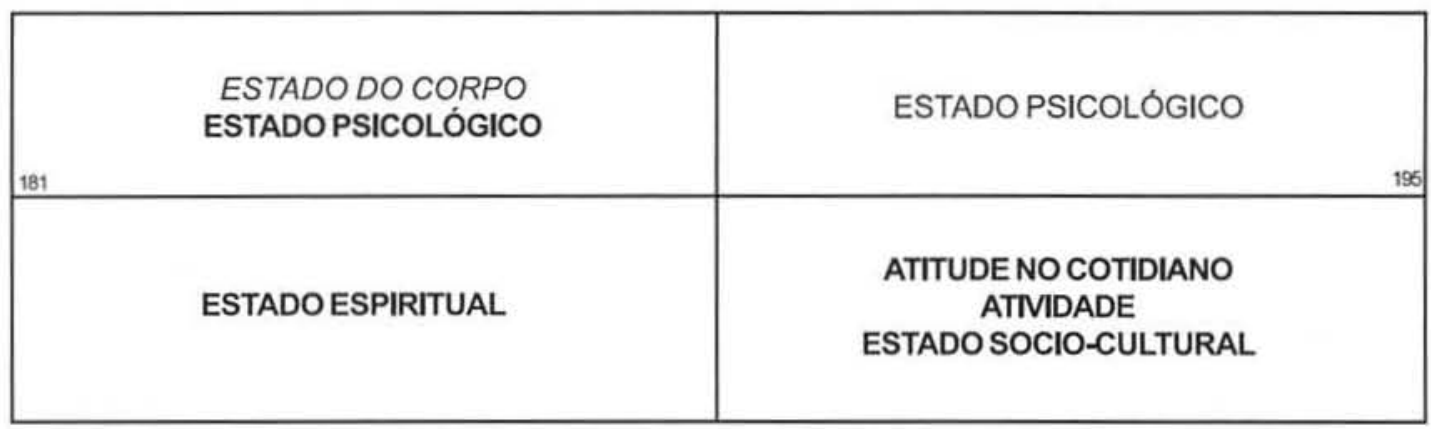

Legenda: Itálico=Categorias de Saúde Normal=Categorias de Doença Negrito=Categorias Comuns

A análise das categorias em torno das quais se agrupam as evocações de saúde e de doença possibilita uma compreensão mais sintética dos conteúdos que formam as representações de saúde e de doença, na medida em que todos os termos evocados foram submetidos ao processo de categorização, sem a exclusão dos termos com baixa freqüência, que ficam abaixo da linha de corte e não são considerados na análise geral das evocaçōes. Assim, essa nova análise pode revelar elementos que, mesmo com freqüências isoladas reduzidas, indiquem conteúdos importantes na medida em que venham a reforçar categorias previamente definidas ou produzir novas categorias quando agrupados.

A comparação apresentada acima evidencia algumas dimensões e contornos das representações de saúde e de doença. Assim, não parecem se configurar duas representações autônomas para saúde e para doença, mas representações polarizadas, caracterizadas pela oposiçäo (positivo-negativo) observada entre os termos que compöem as categorias.

A quase totalidade das categorias se localiza nos mesmos quadrantes quanto aos dois "objetos" - saúde e doença -, porém com sentidos opostos para cada um deles, conforme pode ser observado em Estado psicológico, Estado espiritual, Atitude no cotidiano, Atividade e Estado sócio-cultural. Apenas a categoria Estado do corpo se situa em quadrantes diferentes para saúde e para doença. 
O núcleo central da representação é, pois, formado pela categoria Estado psicológico, para os dois termos indutores, e pela categoria Estado do corpo, apenas para saúde. Isto aponta para uma associação das dimensões fisica e psicológica à saúde e, destacadamente, da dimensão psicológica à doença, o que já se encontrava indicado na análise das evocações de doença, em que termos psicológicos estiveram mais presentes do que nas evocações de saúde.

Na periferia próxima - ou seja, nos elementos intermediários -, observa-se a categoria Estado do corpo apenas na análise da doença, enquanto Estado espiritual se apresenta como categoria comum tanto para a saúde quanto para a doença.

Na periferia das representações analisadas, não se observam categorias especificas de uma ou outra concepção. Estão ai presentes as concepções de saúde e de doença como Atitude no cotidiano, Atividade e Estado sócio-cultural.

O terceiro conjunto de dados realizados foi composto pela análise de similitude (VERGÉS, 1997) das categorias constituidas para os termos "saúde" e "doença", conforme pode ser observado nos gráficos abaixo:

GRÁFICO 2 - ANÁLISE DE SIMILITUDE (ÁRVORE MÁXIMA) AO TERMO INDUTOR "SAÚDE", MONTEIRO LOBATO E SANTO ANTÔNIO DO PINHAL - SĀO PAULO - 2000

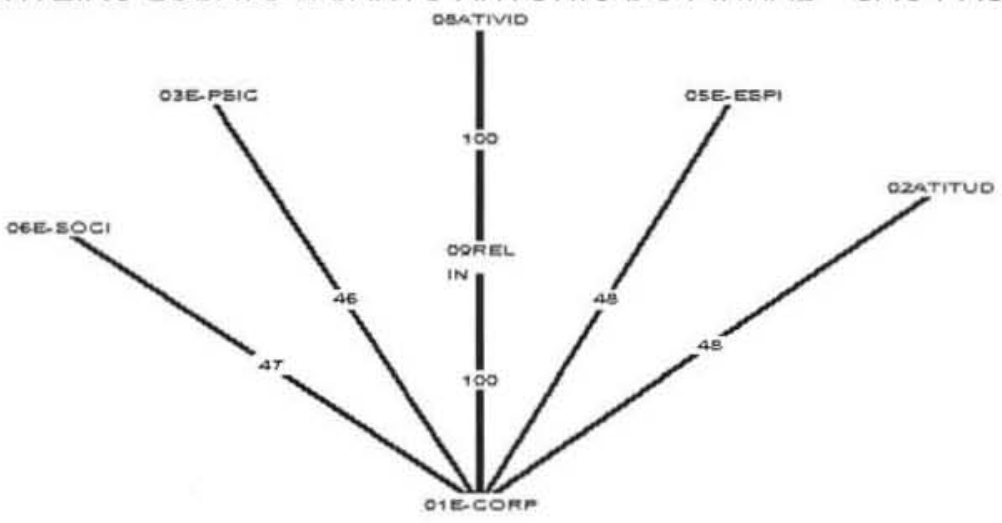

GRÁFICO 3-ANÁLISEDE SIMILITUDE (ÁRVORE MÁXIMA)AO TERMO INDUTOR "DOENÇA", MONTEIRO LOBATO E SANTO ANTÔNIO DO PINHAL - SĀO PAULO - 2000

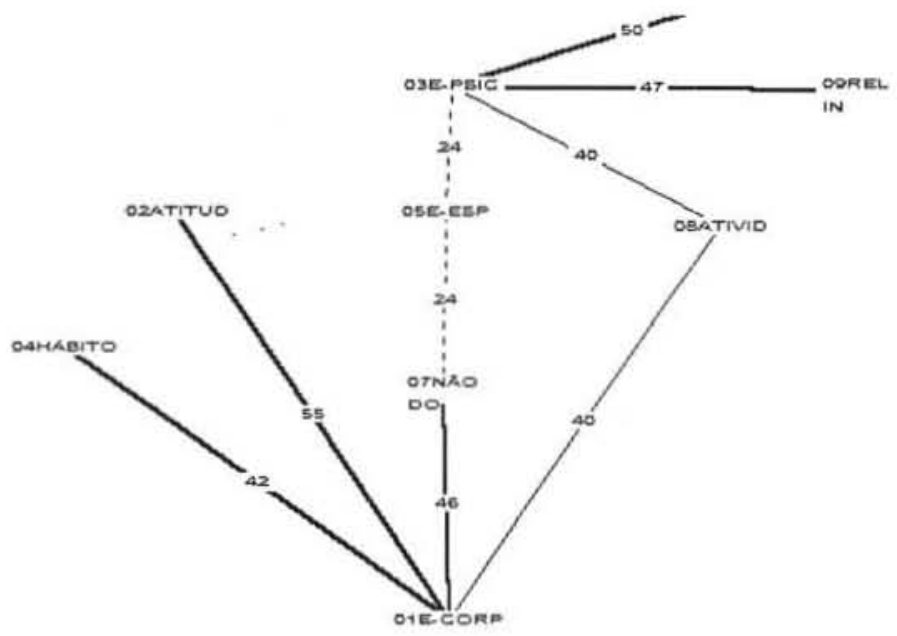


Os gráficos de árvore máxima da representação, apresentados acima, revelam que a categoria "estado do corpo" organiza os outros termos da representação. No entanto, essa função organizadora é exclusiva dessa categoria no termo indutor saúde e associa-se numa ligação triangular a categoria "estado psicológico", na análise do termo doença. A ligação triangular citada estabelece-se entre as categorias "estado do corpo - estado psicológico - atividade", revelando uma configuração mais complexa da representação de doença, se comparada com o termo saúde.

$\mathrm{Na}$ análise do termo saúde, observa-se que a categoria "estado do corpo" está mais fortemente ligada à categoria "atividade", indicando uma concepção de saúde fortemente associada a uma dimensão funcional do corpo; diferentemente de doença, onde observa-se que essa dimensão funcional assume outra configuração ao estabelecer uma ligação com a categoria "estado psicológico", atribuindo um sentido menos físico e mais humano às representações de doença.

O que se pode concluir da co-ocorrência das categorias é uma hipótese de que não se configuram representações autônomas para os objetos saúde e doença, mas sim representações bipolares, com alguns elementos frágeis de especificação de uma e outra concepção. Cabe talvez destacar, nesse sentido, o caráter psicológico da doença, que se expressa sob a forma de necessidades psicossociais comprometidas pela doença, mais do que em função das necessidades físicas ou biológicas.

Por outro lado, evidencia-se a ausência de agressores externos como conteúdos representacionais, como virus e bactérias, ou mesmo outros agentes físicos. Apenas as agressões sociais são reconhecidas como associadas tanto à saúde quanto à doença. Predominam os elementos psicológicos e os biológicos, bem como a confirmação da dimensão espiritual como constitutiva da representação, mas não no seu núcleo central, como aparece na análise direta das evocações.

\section{CONCLUSÕES}

O desafio proposto neste trabalho implicou na defesa de uma proposição, segundo a qual a identificação das representações sociais pode se revelar como uma forma proveitosa de acesso às necessidades humanas/de saúde, contribuindo, assim, para a instrumentalização do campo de atuação da enfermagem.

Tomar as necessidades humanas na sua dimensão de autonomia significa compreender que elas só podem ser definidas pelos sujeitos que as geram. Não obstante, é necessário conceber um limiar humano, portanto social, para as necessidades consideradas no seu pólo coletivo. Isto, na medida em que uma resposta social geradora de preocupação ativa e genuina em relação aos problemas de saúde só pode se constituir a partir da negociação de interesses e vontades profissionais e dos clientes/pacientes. A relação estabelecida entre atos de saúde e a satisfação de necessidades exige a critica concreta ao modo como estas são traduzidas, apresentadas e incorporadas no trabalho em saúde e, especificamente, de enfermagem. Importa superar a sua definição a partir de critérios técnicos e ahistóricos, segundo os quais as demandas são tidas como distintas das necessidades, concebidas as primeiras como falsas e as segundas como verdadeiras.

Nesse sentido, o que observamos no desenvolvimento do presente estudo foi a busca de uma compatibilização sócio-conceitual entre as "demandas" vivas dos clientes, expressas pelas suas representações, e as "necessidades" tradicionalmente reconhecidas pelo saber de enfermagem, alicerçadas pelo conhecimento científico. Neste estudo, o "momento vivido" e seus "significados" são expressos pelas representações dos entrevistados, que "falam" das suas próprias necessidades e expectativas de cuidados de saúde.

As representações caracterizadas indicam que o alvo da intervenção em enfermagem 
precisa ser deslocado do corpo em desequilibrio para os sujeitos, a partir das suas condições concretas - objetivas e subjetivas - de existência. Para isso, é necessário avançar de uma valorização da dimensão biológica humana para uma valorização da dimensão psico-emocional e social (conforme observado nos elementos centrais de saúde e doença). Isto, sem alienar o individuo/sujeito do seu contexto de vida, pois, se tomadas essas dimensões como fatores isolados no individuo, com a finalidade de ordenar a ação profissional, mantém-se uma situação de primazia do conhecimento técnico sobre o conhecimento do senso comum, assim como a relação de desigualdade ora existente entre eles.

As necessidades em saúde, de expressão coletiva, não podem ser isoladas e individualizadas, já que elas apenas assumem sentido no corpo social onde são geradas. Os espaços e tecnologias de trabalho em saúde se destinam a abranger o espaço individualizado e o coletivo, a partir das determinações do processo saúde-doença, mas não apenas delas. Está também implicada nesse processo a subjetividade coletiva constituida, considerando que as necessidades de saúde extrapolam categorias identificáveis em nivel individual. Isto não significa negar a importância da manifestação/satisfação de necessidades individuais, particulares, ou mesmo de uma ação individualizada. Ao contrário, significa valorizar a ação profissional a partir de uma perspectiva onde esses elementos se integrem ao fazer junto a sujeitos sociais concretos. De fato, uma visão da totalidade e da historicidade humana requer o questionamento do modo como se identificam as necessidades, do modo como elas são explicadas e das intervenções assumidas na sua satisfação.

A identificação e a análise das diferentes necessidades dos vários sujeitos ou segmentos sociais, nos espaços coletivos e individualizados, devem orientar as decisões acerca de quais ações e processos devem ser encaminhados para o seu enfrentamento, bem como para a definição das tecnologias de trabalho mais adequadas a esse objetivo. Dessa forma, os instrumentos de trabalho devem permitir a identificaçăo social das necessidades de saúde.

Defendemos aqui a utilizaçäo das representaçōes sociais para a identificação das necessidades de saúde. Essas representações, acessadas a partir de profissionais e dos sujeitos coletivos da atenção à saúde, permitem a definição das necessidades em saúde, numa relação de confronto produtivo, geradora de uma ação pactuada entre profissionais e população. Assim, considerando o referencial teórico adotado neste trabalho, a definição de necessidades humanas como direitos precisa levar em conta a construção da autonomia dos sujeitos individuais e coletivos, tomando-se ela própria, a autonomia, como necessidade humana fundamental. Isto porque é urgente construir um mundo onde as pessoas possam lutar por uma nova ordem social e por relações intersubjetivas igualitárias.

Nesse sentido, vale destacar a importância de avançar no desafio de construção de uma atenção à saúde que leve em conta a multidimensionalidade humana, relevando as suas implicações para as práticas profissionais e institucionais. A construção de uma nova subjetividade profissional implica, portanto, em rever necessidades e também tecnologias de trabalho, incluindo nestas a dimensão subjetiva caracteristica do humano que é o profissional, e da clientela por ele atendida no campo da saúde. Dessa forma, à reinterpretação das necessidades e à mudança na processualidade da sua definição, seguir-se-á o desafio da construção de tecnologias/ processos de trabalho adequados, ou seja, da especificação de quais ferramentas, quais processos, quais saberes, qual intersubjetividade, são mais adequados à construção dessa nova racionalidade, de implantação tão premente no campo do conhecimento e das práticas profissionais de saúde.

Se desejamos transformar uma dada realidade, é necessário pensá-la em suas expressões objetiva e subjetiva, uma vez que as estratégias de intervenção em saúde säo efetivadas por pessoas, que agem segundo suas representaçöes do real e também segundo suas representações do possivel. Transformar as açöes, portanto, implica em transformar as representações que as orientam. Esse processo de transformação não se dá apenas através 
da evolução cientifica ou da educação em saúde, mas como resultado de um processo ativo onde as "necessidades" são reconstruidas em um contexto de associações e de valores.

Pensar um novo projeto para a saúde exige reconhecer a diversidade de ações, a partir da qual cabe a cada profissional uma contribuição especifica na abordagem do sujeito coletivo, o que implica em estabelecer um modelo assistencial capaz de viabilizar os objetivos desejados. Esta é uma função de todos e tem início no reconhecimento da distância entre representações sociais, práticas cotidianas e conhecimento cientifico. Assim, é importante destacar que não é apenas a realidade objetiva da situação que permite entendê-la, mas também a maneira como os grupos se apropriam dela. Buscar alternativas ao modelo assistencial vigente, tomando as representações sociais como base de análise, pode contribuir para a prevenção de conflitos sócio-profissionais gerados pela oposição às representações do senso comum. Por outro lado, uma reflexão aprofundada sobre esse mesmo objeto pode conduzir a um caminho proficuo na transformação das práticas profissionais.

Talvez um elemento importante a lembrar, que está na base da teoria das representaçōes sociais, é que o seu processo de mudança é lento. Primeiramente são transformados os elementos periféricos da representação, para somente depois os elementos centrais serem modificados, quando chegam a sê-lo de fato. Isto quer dizer que as representações se transformam mais lentamente do que as oscilações das realidades sociais, politicas e econômicas. Nesse sentido, uma proposta de mudança de modelos que se pretenda efetivar precisa levar em consideração o lapso de tempo necessário para a transformação das representaçōes que devem acompanhá-los, bem como os fatores que possam contribuir para a efetivação de tais transformaçōes.

Não obstante, devemos acentuar que, para intervir na atual configuração das práticas de enfermagem de forma a auxiliar na reorganização dos serviços de saúde, é preciso facilitar o reconhecimento pelos atores sociais do seu próprio papel na produção imaginária dos processos de saúde. Em outras palavras, os problemas de saúde não estão simplesmente "lá fora" para serem enfrentados, não existem duas coisas, tais como as necessidades da população e o instrumental técnico para o atendimento dessas necessidades. É a estrutura social em que vivemos todos, integrada àquela na qual os profissionais trabalham, associadas ainda às nossas respectivas subjetividades, que determinam a leitura que pode ser feita da realidade e das necessidades que a perpassam.

Dessa forma, práticas profissionais que pretendam abarcar os planos aqui analisados têm forçosamente como pressuposto básico a necessidade de organização dos serviços de saúde como lugares que possam estar, ao mesmo tempo, produzindo e transformando representações. Para a delimitação das necessidades humanas/de saúde como instrumento conceitual de trabalho é preciso construi-las conjuntamente, possibilitando assim que profissionais e comunidades, bem como a própria sociedade de forma mais ampla, atuem sobre a sua configuração.

Concluindo, acreditamos que é preciso buscar a ampliação do poder de aproximar-se empaticamente da realidade dos usuários dos serviços de saúde. Para isso, é preciso que as representações se tornem transparentes para os seus próprios sujeitos, produtores e usuários, tendo em vista que os mesmos possam retomá-las no seu valor de significado. Por outro lado, isto significa tomar as necessidades humanas/de saúde como elementos sociais construtores e construidos, determinantes e determinados pelas realidades vivenciadas no cotidiano dos clientes/pacientes e dos profissionais dos serviços de saúde.

ABSTRACT: This study characterizes the social representations of the health-disease process of subjects resident in two districts of São Paulo, in order to identify the needs of health and the orientation of the nursing action. Free evocations recollections from 418 adults on the themes health and disease. Data analyse was developed thought a descriptive and structural analysis of the social representations, 
through the methodology of construction of the "picture of four houses", categorization and similitude analysis. The results show central senses of the representation, the positiveness of the health, are anchored in a divine entity, and accompanied of notions that associate health to prevention of diseases, to biological needs, to activity and to which the attitude assumed to the disease. The representation structure of disease is similar, in inverse sense, to the one of the health: god is the center of the social representation, in its negative version, being expressed in the body through the pain, of the death and the inactivity and - in the spirit - through the sadness and of the depression. The discussion is that psychological character of health and of disease, that is expressed under the psicossocials needs committed, and the consequent need of rethinking the technological model of work in nursing.

KEYWORDS: care taking in nursing, basic human needs, health-disease process, Social Representations

RESUMEN: El estudio objetiva la caracterización de las representaciones sociales del proceso saludenfermedad de individuos residentes en dos municipios de São Paulo, con vistas a identificar las necesidades de salud y a la orientación de la acción de enfermeria. Se recolectaron evocaciones libres de 418 adultos sobre los temas "salud" y "enfermedad". Se realizó un análisis descriptivo y estructural de las representaciones sociales, a través de la metodología de construcción del cuadro de cuatro casas, categorización y análisis de similitud. Los resultados indican como sentidos centrales de la representación, la positividad de la "salud", anclada en una entidad divina, acompañada de nociones que asocian la salud a la prevención de enfermedades, a necesidades biológicas, a la actividad y a la actitud asumida frente a la enfermedad. La estructura de la representación de "enfermedad" se presenta semejante, sino que en sentido inverso a la de la "salud": dios es estructurador de la representación, en su versión negativa, y se expresa en el cuerpo a través del delor, de la muerte y de la inactividad y en el espiritu, a través de la tristeza y el desánimo. Se discute el carácter psicológico de la salud y de la enfermedad, que se expresa bajo la forma de necesidades psicosociales comprometidas, y la consecuente necesidad de repensar el modelo tecnológico de trabajo en enfermeria.

PALABRAS CLAVE: cuidar en enfermeria, necesidades humanas básicas, proceso saludenfermedad, Representaciones Sociales

\section{REFERÊNCIAS BIBLIOGRÁFICAS}

ABRIC, J. C. Coopération, compétition et représentations sociales. Cousset: DelVal, 1987.

ABRIC, J. C. Pratiques sociales et représentations. Paris: Presses Universitaires de France, 1994.

ABRIC, J. C. A abordagem estrutural das representações sociais. In: MOREIRA, ASP; OLIVEIRA, DC (Org.). Estudos interdisciplinares de representação social. Goiânia: AB Editora, 1998. p. 27-38.

DOISE, W.; CLEMENCE, A.; LORENZI-CIOLDI, F. Représentations sociales et analyses de données. Grenoble: Presse Universitaire de Grenoble, 1992.

FAWCETT, J. Analysis and evaluation of conceptual models or nursing. Philadelphia: F.A. Davis Company, 1995.

FLAMENT, C. L'analyse de similitude: une technique pour les recherches sur les représentations sociales. In: DOISE, W.; PALMONARI, A (Org.). L'Étude des représentations sociales. Neuchâtel: Delachaux et Niestlé, 1986. p. 139-156.

FLAMENT, C. L'analyse de similitude: une technique pour les recherches sur les représentations sociales. Cah. Psychol. Cogn., v. 1, n. 4, p. 375-95, 1981. 
Representações sociais da saúde...

HORTA, WA. Processo de Enfermagem. São Paulo: EPU, 1979.

KRUSKAL, J. B. Multidimensional scaling: a numerical method. Psychometrika, n. 29, p. 01-27, 1964.

JODELET, D. Folies et représentations sociales. Paris: PUF, 1989.

MOSCOVICI, S. La psychanalyse, son image et son public. 2. ed. Paris: PUF, 1976.

SÁ, C. P. Núcleo Central das Representações Sociais. Petrópolis: Vozes, 1996.

SANTOS, BS. Pela mão de Alice: o social e o politico na pós-modernidade. Porto: Edições Afrontamento, 1994.

VERGĖS, P. L'évocation de l'argent: une méthode pour la definition du noyau central de la représentation. Bulletin de Psychologie, v. 45, n. 405, p. 203-09, 1992.

SIMI - Analyse de similitude de questionnaires et de donnees numeriques: Manuel version 1.2. Aix-en-Provence: LAMES, 1997.

Ensemble de programmes permettant l'analyse des evocations: Manuel version 2. Aix-enProvence: LAMES, 1999.

WALDOW, V. R. Cuidado humano: o resgate necessário. Porto Alegre: Sagra Luzzatto, 1998. 